Yusuf Alaşahan, Salih Tosun

Düzce University, Düzce-Turkey

yusufalasahan@duzce.edu.tr; salihtosun@duzce.edu.tr

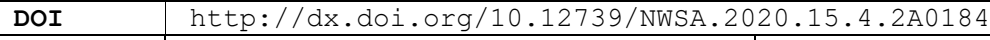

ORCID ID $0000-0001-6929-5319 \quad 0000-0002-5698-6628$

CORRESPONDING AUTHOR Yusuf Alaşahan

\title{
DAĞITILMIŞ SERİ REAKTÖRLERİN(DSR) GÜÇ SİSTEMLERINNE ETKİLERİ
}

\section{öz}

Dağıtılmış Esnek Alternatif Akım İletim Sistemi(DFACTS) cihazları iletim hattına seri olarak bağlanıp hatta reaktans ilave eden cihazlardır. Dağıtılmış Seri Reaktörler (DSR) olarak da ifade edilen aygıtların güç sisteminde hat parametrelerine müdahale ederek, empedans dengesizliğini düzeltme yetenekleri vardır. Ayrıca dengeli yük akışı sonucu gerilim dengelemesi, daha fazla güç aktarımı veya güç sisteminin iletim yeteneğinin daha etkin bir şekilde kullanılmasını da sağlamaktadır. Bu sebeple sistemin boyutlarını genişletmeden yüklenebilirliğini kontrol etmek için kullanımı giderek yaygınlaşmakta ve önem kazanmaktadır. Bu çalışmada DSR aygıtıarının sistem yüklenebilirliği ve gerilim kararlılığı üzerine olan etkileri ile uygulanabilirliğinin analizi yapılmıştır. Analiz, Power World Simülatör Programı kullanllarak Institute of Electrical and Electronics Engineers (IEEE) 6 baralı standart sistemi üzerinde yapılmıştır. Yük akışı yapılarak DSR'nin sistem üzerindeki etkileri araştırılmıştır.

Anahtar Kelimeler: DSR, Güç Sistemleri, Yük Akışı, Gerilim Kararlılığı, Yüklenebilirlik

\section{THE EFFECTS OF DISTRIBUTED SERIAL REACTORS (DSR) ON POWER SYSTEMS}

\section{ABSTRACT}

Distributed Flexible Alternating Current Transmission System (DFACTS) devices are devices that are connected in series to the transmission line and even adding reactance. Devices, also referred to as Distributed Serial Reactors (DSR), have the ability correct impedance imbalance by interfering with line parameters in the power system. In addition, voltage balancing as a result of balanced load flow enables more power transmission or more efficient use of the power system's transmission capability. For this reason, the use of the system to control its loadability without expanding its dimensions is becoming more and more widespread. In this study, the effects of DSR devices on system loadability and voltage stability and their applicability are analyzed. The analysis was carried out on the Institute of Electrical and Electronics Engineers (IEEE) 6-bus Standard system using the Power World Simulator Program. The effects of DSR on the system were investigated by performing load flow.

Keywords: DSR, Power Sysytems, Load Flow, Voltage Stablity, Loadability

How to Cite:

Alaşahan, Y. ve Tosun, S., (2020). Dağıtılmış Seri Reaktörlerin (DSR) Güç Sistemlerine Etkileri, Technological Applied Sciences (NWSATAS), 15(4):50-63, DOI: $10.12739 /$ NWSA.2020.15.4.2A0184. 
1. GİRIŞ (INTRODUCTION)

Enerji sistemlerinde 1970'li yıllarda yaşanan hızlı gelişmelere paralel olarak gerilim kararsızlığı, uzun ve yüklü hatlarda aktif güç kararsızlığı ve frekans kararsızlığı gibi sorunlar ortaya çıkmıştır [2]. $\mathrm{Bu}$ sorunların çözümlenmesi için Esnek Alternatif Akım İletim Sistemleri'nin (FACTS) tanıtımı ilk olarak 1980'li yılların sonunda Amerika'da Elektrik Gücü Araştırma Enstitüsü (Electric Power Research Institute-EPRI) tarafından yapılmıştır. FACTS terimi 1988'de EPRI'den Dr. Narain Hingorani tarafından kullanılmıştır [1, 2 ve 3]. Güç iletiminin esnekliği: Sistemin çalışma koşullarındaki değişikliklere uyum sağlama yeteneği veya sürekli hal ve geçici hal sınır değerlerini belirli bir seviyede tutacak biçimde enerji iletimi olarak tanımlanmıştır [2]. FACTS ise: Güç sisteminin kontrol edilebilirliğini ve güç iletim kapasitesini arttırmak için iletim sistemine ilişkin bir veya daha fazla parametrenin kontrolünü sağlayan güç elektroniği tabanlı bir sistem ve diğer statik donanımdır [1, 2, 3, 4, 5 ve 6]. FACTS kontrolörler güç elektroniği tabanlı olduğundan faz kaydırıcı, şönt kapasitör, seri kapasitör gibi geleneksel mekanik kontrolörlere göre daha hızlıdır. FACTS cihazları iletim hattının seri empedansı, akımı, gerilimi, aktif gücü ve reaktif gücü gibi parametrelerin kompanzasyonu ile güç sisteminin kontrolünü sağlamaktadır. Şekil 1'de genel sembolu verilen FACTS cihazlarının iki ana amacı vardır. Bunlardan birincisi, Sistemin iletim kapasitesini arttırmak, diğeri ise belirlenen iletim hatları üzerinde güç akışı kontrolünü sağlamak [1, 7 ve 8].

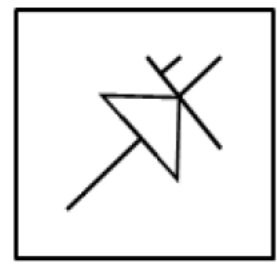

Sekil 1. FACTS cihazlarının genel sembolü [2]

(Figure 1. General symbol of FACTS devices)

\section{2. ÇALIŞMANIN ÖNEMI (RESEARCH SIGNIFICANCE)}

DSR aygıtları mevcut güç sistemlerinin boyutları değiştirilmeden iletim hatlarının yüklenme oranının kontrolü ile aşırı yüklenen iletim hatlarının rahatlatılmasını sağlamakta ayrıca generatörlerden çekilebilecek gücü ve sistemin kararlılık değerlerini kontrol etme olanağı vermektedir. Fiziki ve ekonomik sebeplerle güç sistemlerinin boyutlarının genişletilmesinin giderek zorlaştığı günümüz dünyasında DSR aygıtlarının kullanımı giderek yaygınlaşmaktadır. Bu duruma bağlı olarak DSR aygıtları hakkında bilimsel çalışmalarda hız kazanmaktadır. Bu çalışmada DSR aygıtlarının güç sistemlerinde etkileri ve uygulanabilirliği incelenmiş ve DSR aygıtlarının kullanımı sonucunda iletim hatlarının yüklenme oranları ile sistemin kararlılık değerlerinin değişimine ilişkin sonuçlar ortaya konmuştur.

\section{DSR AYGITI (DSR DEVICE)}

Bir çeşit DFACTS (Distributed Flexible Alternative Current Transmission Sytems) aygıtı olan Dağıtılmış Seri Reaktör (DSR), iletim hattına seri olarak bağlanan, hatta seri reaktans enjekte ederek devrenin seri empedansını arttıran ve nakil hattı iletkeninden indüksiyonla güç sağlayan bağımsız bir cihazdır. DSR, İletim hattı üzerine monte edilir. Her modül önceden tanımlanmış bir ayar noktasında tetiklenebilir veya uzaktan kontrol edilebilir. İlk olarak 2002-2003 yıllarında Yüksek Gerilim (HV) iletim hatlarında pilot olarak uygulanmıştır. DSR aygıtları güç sisteminin iletim kapasitesinin arttırılmasını sağlamaktadır. Bu 
sebeple mevcut sistemin boyutlarını genişletmeden yüklenebilirliğini kontrol etmek için kullanımı giderek yaygınlaşmakta ve önem kazanmaktadır. DSR uygulamaları ile sistemden çekilebilecek güç arttırılabilir. Enerji nakil hatlarının sınır değerlerde çalıştırılmadığı durumlarda gerilim dengesizlikleri azaltılabilir. Sistemin yüklenebilirliğinin kontrolünün sağlanmasıyla, sistemin toplam işletim maliyeti düşürülebilmektedir [6, 9, 10, 12, 13, 14 ve 15]. Birçok FACTS kontrolörü aktif empedans enjeksiyonu yapar. Aktif empedans enjeksiyonu, AC gerilim enjekte edilerek elde edilen seri veya şönt kompanzasyonun her ikisini de tanımlamak için kullanılan bir terimdir. Voltaj enjeksiyonu, iletim hattı üzerinde yapılandırılabilen bir Senkron Gerilim Kaynağı (Synchronous Voltage Source-SVS) kullanılarak gerçekleştirilir. Senkron Gerilim Kaynağı, genlik ve faz açısı kontrol edilebilen temel frekanslı sinüsoidal gerilim üretir. Şekil 2'de görüldüğü gibi enjekte edilen voltaj büyüklüğünü kontrol ederek reaktif güç üretebilir veya tüketebilir [11 ve 15].

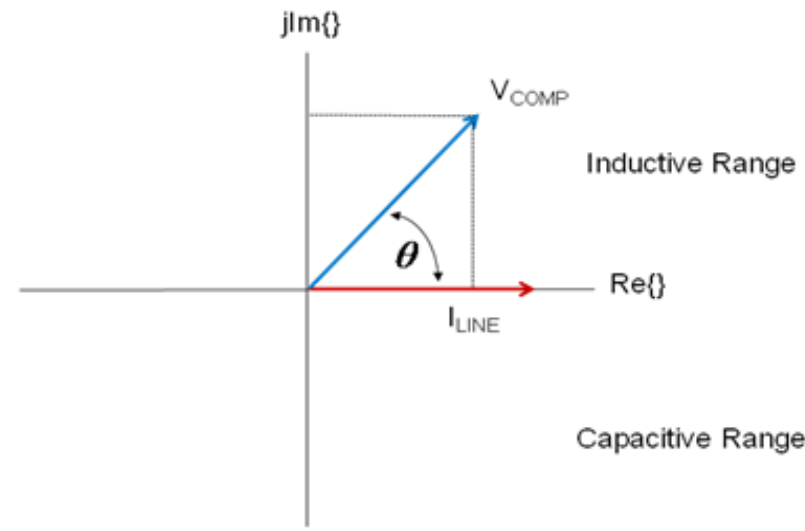

Şekil 2. Kompanzasyon geriliminin değişimi [11]

(Figure 2. Insertion of a compensating voltage)

Enjekte edilen gerilim ( $V_{\text {COMP }}$ ) ile hat akımı ( $I_{\text {LINE }}$ ) arasında $90^{0}$ faz farkı olduğunda SVS kondansatör veya bobin gibi davranır ve sadece reaktif güç değiştirilebilir. Enjekte edilen gerilim ( $V_{\text {Comp }}$ ) ile hat akımı

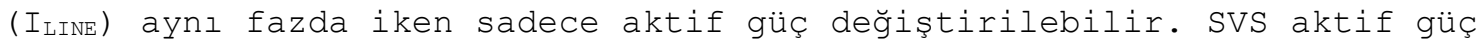
oluşturamaz bu sebeple aktif güç harici bir kaynaktan sağlanmıyorsa $\left(V_{\text {CомP }}\right)$ ile hat akımı ( $I_{\text {LINE}}$ ) arasında $90^{\circ}$ faz farkı olmalıdır. Eğer harici bir kaynaktan veya yük bağlı ise hat akımına göre gerilim genliğini kontrol ederek aktif gücün değiştirilmesi mümkündür [11]. Reaktif güç kompanzasyonu için gerilim kaynağı kullanılması, seri kapasitörün etkisinin kavranmasıyla anlaşılabilir. Hat üzerindeki seri kapasitör hat boyunca oluşan endüktif gerilim düşümünün bir kısmını yok etmek için gerekli olan temel frekensli gerilimi hatta verir. Denklem (1)'de verilen kapasitör üzerindeki gerilim düşümü ifadesi göz önüne alınırsa seri kapasitör ile aynı etki hat akımıyla arasında $90^{0}$ faz farkı olan bir AC gerilim kaynağı ile elde edilebilir [11].

$$
V_{C}=-J I\left[\frac{1}{\omega C}\right]=-J I X_{C}
$$

DSR aygıtı bir AC gerilim kaynağı gibi görev yapmaktadır. Şekil 3'te DSR'nin iletim hattına bağlantısı ve Şekil 4'te ise iletim hattı üzerine uygulanışı gösterilmiştir. 
Transformer Primary

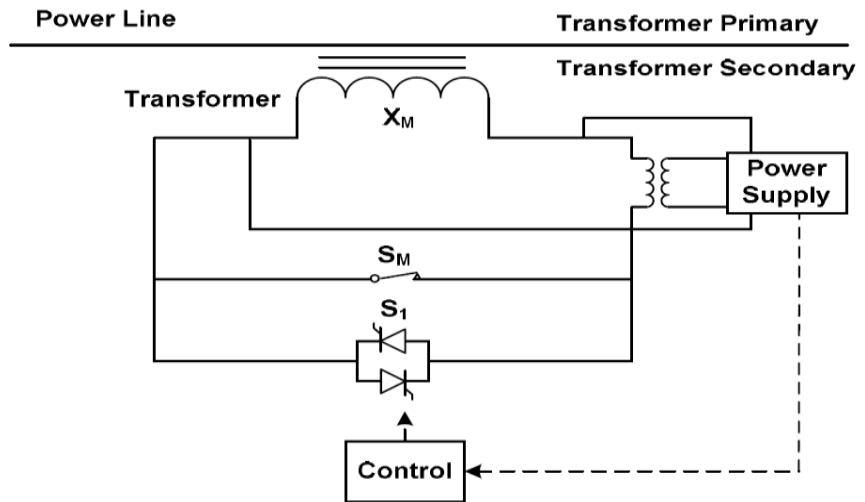

Şekil 3. DSR cihazının devre şeması [6, 10, 14 ve 15] (Figure 3. Ciruit diagram of DSR device)

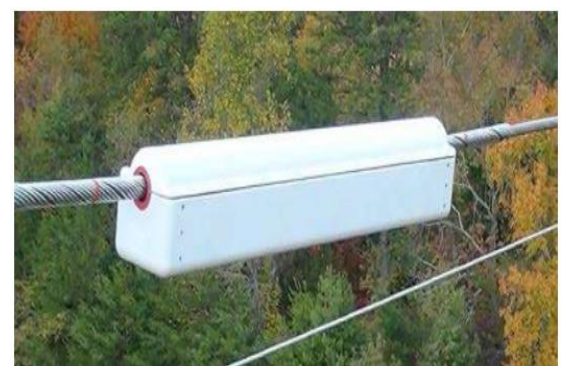

Şekil 4. (a)

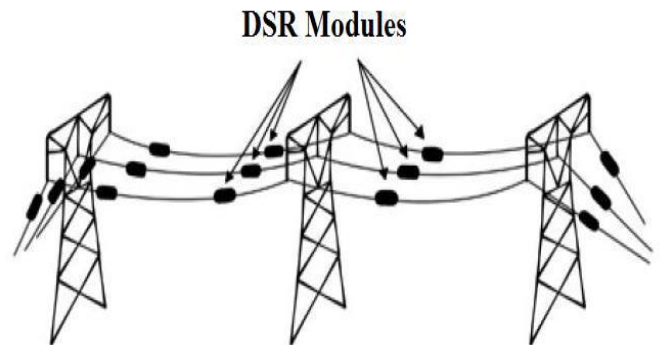

Şekil 4. (b)

Sekil 4. (a) İletim hattına monte edilmiş DSR modülü [9 ve 15]

(b) iletim hattı üzerinde DSR modüllerinin şematik gösterimi [9 ve 10]

(Figure 4. (a) DSR device of mounted on the transmission line

(b) Schematic shown of DSR devices on the transmission line)

\section{ANALITTIK ÇALIŞMA (ANALYTICAL STUDY)}

Bu çalışmada IEEE'nin şekil 4'te verilen 6 Baralı standart güç sistemi üzerinde DSR aygıtı olmadan ve DSR aygıtı ilave edilerek gü̧̧ akışı simülasyonu yapılmıştır. Yapılan simülasyon sonucunda elde edilen değerlere göre yük baralarının P-V eğrileri oluşturulmuş ve sonuçlar incelenmiştir. Analiz çalışmaları Power World Corporation'nun lisanslı ürünü olan Power World Simülatör Programı kullanılarak yapılmıştır.

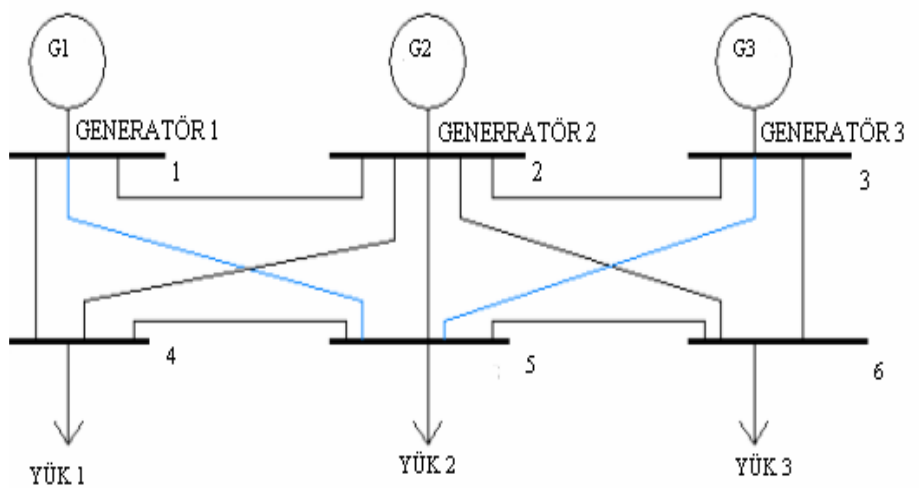

Şekil 5. IEEE 6 baralı sistemi tek hat şeması [16]

(Figure 5. Single line diagram of IEEE 6 buses system

Verilen güç sisteminde 1 nolu bara salınım barası (SB) olarak alınmıstır. 2 ve 3 nolu baralar generatör barası (PV) olarak verilmiștir. Geri kalan 4, 5 ve 6 nolu baralar ise yük barası (PQ) olarak verilmiştir. 
Altı baralı güç sisteminin iletim hattı, generatör ve bara verileri Tablo 1, 2 ve 3'te verilmiştir.

Tablo 1. IEEE 6 baralı sistemi hat verileri [16]

(Table 1. Line data of IEEE 6 buses system)

\begin{tabular}{|c|c|c|c|}
\hline Hat No & $\mathrm{R}(\mathrm{pu})$ & $\mathrm{X}(\mathrm{pu})$ & $\mathrm{B}(\mathrm{pu})$ \\
\hline $1-2$ & 0.1 & 0.2 & 0.04 \\
\hline $1-4$ & 0.05 & 0.092 & 0.04 \\
\hline $1-5$ & 0.08 & 0.2 & 0.06 \\
\hline $2-3$ & 0.05 & 0.25 & 0.06 \\
\hline $2-4$ & 0.05 & 0.1 & 0.02 \\
\hline $2-5$ & 0.1 & 0.3 & 0.04 \\
\hline $2-6$ & 0.07 & 0.2 & 0.05 \\
\hline $3-5$ & 0.12 & 0.26 & 0.05 \\
\hline $3-6$ & 0.02 & 0.1 & 0.02 \\
\hline $4-5$ & 0.2 & 0.4 & 0.08 \\
\hline $5-6$ & 0.1 & 0.3 & 0.06 \\
\hline
\end{tabular}

Tablo 2. IEEE 6 baralı sistemi generatör verileri [17]

(Table 2. Generator data Of IEEE 6 buses system)

\begin{tabular}{|c|c|c|c|c|c|c|}
\hline $\begin{array}{c}\text { Generatör } \\
\text { Bara No }\end{array}$ & $\begin{array}{c}\text { Aktif } \\
\text { Gü̧c } \\
\text { Üretimi } \\
\text { (MW) }\end{array}$ & $\begin{array}{c}\text { Reaktif } \\
\text { Güç } \\
\text { Üretimi } \\
\text { (MVAR) }\end{array}$ & $\begin{array}{c}\text { Maksimum } \\
\text { Aktif Güç } \\
\text { Üretimi } \\
\text { (MW) }\end{array}$ & $\begin{array}{c}\text { Minimum } \\
\text { Aktif Güç } \\
\text { Üretimi } \\
\text { (MW) }\end{array}$ & $\begin{array}{c}\text { Maksimum } \\
\text { Reaktif } \\
\text { Güç } \\
\text { Üretimi } \\
\text { (MVAR) }\end{array}$ & $\begin{array}{c}\text { Minimum } \\
\text { Reaktif } \\
\text { Güç } \\
\text { Üretimi } \\
\text { (MVAR) }\end{array}$ \\
\hline 1 & 0 & 0 & 200 & 50 & 100 & -100 \\
\hline 2 & 50 & 0 & 150 & 37.5 & 100 & -100 \\
\hline 3 & 60 & 0 & 180 & 45 & 100 & -100 \\
\hline
\end{tabular}

Tablo 3. IEEE 6 baralı sistemi bara verileri [17]

(Table 3. Bus data of IEEE 6 buses system)

\begin{tabular}{|c|c|c|c|c|c|c|c|c|}
\hline $\begin{array}{c}\text { Bara } \\
\text { No }\end{array}$ & $\begin{array}{c}\text { Bara } \\
\text { Tipi }\end{array}$ & $\begin{array}{c}\text { Gerilim } \\
\text { Genliği } \\
\text { (pu) }\end{array}$ & $\begin{array}{c}\text { Gerilim } \\
\text { Açlsı } \\
\text { (Derece) }\end{array}$ & $\begin{array}{c}\text { Yük } \\
\text { Aktif } \\
\text { Gücü } \\
\text { (MW) }\end{array}$ & $\begin{array}{c}\text { Yük } \\
\text { Reaktif } \\
\text { Gücü } \\
\text { (MVAR) }\end{array}$ & $\begin{array}{c}\text { Şönt } \\
\text { Kapasitan } \\
\text { S } \\
\text { (MVAR) }\end{array}$ & $\begin{array}{c}\text { Maksimum } \\
\text { Gerilim } \\
\text { Genliği } \\
\text { (pu) }\end{array}$ & $\begin{array}{c}\text { Minimum } \\
\text { Gerilim } \\
\text { Genliği } \\
\text { (pu) }\end{array}$ \\
\hline 1 & SB & 1.05 & 0 & 0 & 0 & 0 & 1.1 & 0.9 \\
\hline 2 & $\mathrm{PV}$ & 1.05 & 0 & 0 & 0 & 0 & 1.1 & 0.9 \\
\hline 3 & $\mathrm{PV}$ & 1.07 & 0 & 0 & 0 & 0 & 1.1 & 0.9 \\
\hline 4 & $\mathrm{PQ}$ & 1 & 0 & 70 & 70 & 0 & 1.1 & 0.9 \\
\hline 5 & $\mathrm{PQ}$ & 1 & 0 & 70 & 70 & 0 & 1.1 & 0.9 \\
\hline 6 & $\mathrm{PQ}$ & 1 & 0 & 70 & 70 & 0 & 1.1 & 0.9 \\
\hline
\end{tabular}

\subsection{Power World Simülatör (Power World Simulator)}

Power World programında farklı güç sistemleri için yük akışı analizleri yapılabilmektedir. Programda güç sistemini oluşturan generatör, hat, bara ve yük gibi tüm bileşenlerin birer simgesi(çizim elemanı) mevcuttur. Önce bu elemanlar ile sistem çizilir sonra da her elemana ilişkin veriler girilir. Program, girilen bilgilere göre yük akışı hesaplamalarını yapar. Program yük akış çözümü sayesinde; her hattan akan Aktif Güç (MW) ve Reaktif (MVAr) Güç değerlerini, Statik kapasitör ve reaktörlerden akan güç değerlerini hesaplar. İstenilirse generatörlerin reaktif (MVAr) gücü sınırlandırılabilir, istenilen bara salınım barası olarak değiştirilebilir. Ayrıca her hat için aktif ve reaktif kayıplar ile sistemdeki toplam kayıplar hesaplanır [18 ve 19].

\subsection{P-V Eğrilerinin Elde Edilmesi (The Obtain of P-V Curves)}

Güç katsayısı ve hat başı gerilimi sabit olmak üzere hat sonunda yük barası aktif güç değerinin sıfırdan başlayarak adım adım arttırılması ve yük barası gerilim genlik değerinin aktif güce bağlı değişiminin grafik olarak çizilmesi ile P-V eğrileri elde edilir. P-V eğrileri ile 
güç sisteminin kritik değerleri belirlenebilir. P-V eğrilerinin çizilebilmesi için hat sonu gerilimi ile hat sonu aktif güç değeri arasındaki ilişki $a x^{2}+b x+c=0$ şeklinde ikinci dereceden eşitlik formunda ifade edilir. Bu eşitliğin elde edilmesi için iletim hattı parametreleri hesaplanır ve sabit kabul edilir. Baralara ait aktif güç, reaktif güç ve gerilim genlik değerleri de yük akışı verilerinden alınır. Bir bilgisayar programı ile elde edilen eşitliğin grafiği çizildiğinde P-V eğrisi elde edilmiş olur [6]. İletim hattının Şekil 6'da verilen iki kapılı devre modeli göz önüne alındığında; sırasıyla $V_{s}$ : generatör barası gerilimi ve akımı; $V_{r}, I_{r}$ : yük barası gerilimi ve akımı; A, B, C, D: Uzun iletim hattı sabitleri olmak üzere güç sistemine ilişkin denklem (2) elde edilir [16].

$$
V_{s}=A V_{r}+B I_{r}
$$

Burada Sr, Pr, Qr sırasıyla yükün görünür, aktif ve reaktif güç değerleri olmak üzere

$$
\begin{aligned}
& S_{r}=P_{r}+J Q_{r}=V_{r} I_{r}^{*} \\
& I_{r}^{*}=\frac{P_{r}+J Q_{r}}{V_{r}} \Rightarrow I_{r}=\frac{P_{r}-J Q_{r}}{V_{r}^{*}}
\end{aligned}
$$

Şeklinde ifade edilir [6]. Denklem (2)' de sağ taraftaki ifadelerin açık halleri yazılıp gerekli işlemler ve düzenlemeler yapılırsa (5) nolu denklem elde edilir [16 ve 20].

$$
\begin{aligned}
& |A|^{2}\left|V_{r}\right|^{4}+\left[2 P_{r}\left(a_{1} b_{1}+a_{2} b_{2}\right)+2\left(p_{r} \tan \varphi\right)^{2}\left(a_{1} b_{2}-a_{2} b_{1}\right)\right]\left|V_{r}\right|^{2}+|B|^{2}\left(P_{r}^{2}+\left(p_{r} \tan \varphi\right)^{2}\right)=\mathrm{O} \text { (5) } \\
& \text { Bu ifadede }\left|V_{r}\right|^{2}=X \text { olarak düşünülürse (5) nolu eşitlik }
\end{aligned}
$$

$a x^{2}+b x+c=0$ şeklinde 2. dereceden bir eşitlik formuna gelmiş olur. Uzun iletim hattı sabitlerinin hesaplanmasl ile $a_{1}, a_{2}, b_{1}, b_{2}, A$ ve $B$ katsayıları elde edilir. Güç katsayısı sabit olduğundan yükün güç açısı $\varphi$ değeri de bilinmektedir. Yük barasının aktif gücü $P_{r}$ 'nin sıfırdan itibaren adım adım arttırılması ile her defasında ikinci dereceden eşitlik çözülür ve eşitlikte bilinmeyen değişken olan $\left|V_{r}\right|$ hesaplanır. Eksenlerden biri aktif gücü diğeri de gerilim genlik değerini göstermek üzere hesaplanan değerlerin grafiği çizildiğinde yük barasının P-V eğrisi elde edilmiş olur [16 ve 20] •

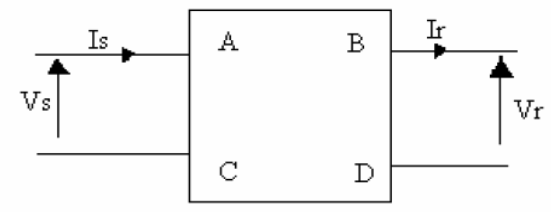

Şekil 6. İletim hattı iki kapılı devre modeli [16]

(Figure 6. Two gate circuit model of transmission line)

Burada eşitlik (5)'teki iletim hattı parametrelerinin (A, B, C, D) hesaplanabilmesi için gerekli olan hat empedansı ( $Z_{h}$ ) ve hat admitansı $\left(Y_{h}\right)$ değerlerinin elde edilmesi gereklidir. Bunun için ise güç sisteminin salınım barası ve kritik değerleri incelenen yük barasından oluşan 2 baralı tek hatlı sisteme indirgenmesi gerekir. Bu işlem Bara İndirgeme Yöntemi ile yapılır [16].

\subsection{Bara İndirgeme Yöntemi (The Method of Reduce to Bus)}

Bara sayısı $n$ olmak üzere sistemde salınım barası ile kritik değerleri aranan yük barası dışındaki diğer tüm baralara ait aktif ve reaktif güçler admitans değerlerine çevrilip bara admitans matrisinin 
ilgili ana köşegen elemanına eklenir. Elde edilen yeni bara admitans matrisi üzerinde indirgeme işlemi yapılarak admitans matrisi 2x2 boyutuna indirgenir. Daha sonra Bölüm 4.2'de verilen (5) nolu eşitliğin kullanılmasıyla sistemin P-V eğrisi elde edilir. Bara İndirgeme Yöntemi İslem Adımları şöyle ifade edilebilir: Sistemin herhangi bir andaki değerler ile güç akışı yapılarak baralara ait aktif güç, reaktif güç ve gerilim genlik değerleri elde edilir. Salınım barası ve kritik değerleri incelenen yük barası dışındaki tüm baraların aktif ve reaktif güçleri (6), (7), (8) ve (9) nolu denklemler kullanılarak admitans değerlerine dönüştürülür [16].

$$
\begin{aligned}
& S_{i}=P_{i}+j Q_{i} \\
& \varphi_{i}=\tan ^{-1}\left(\frac{Q_{i}}{P_{i}}\right) \\
& Z_{i}=\frac{V_{i}}{I_{i}} e^{j \varphi}=\frac{V_{i}^{2}}{V_{i} I_{i}} e^{j \varphi}=\frac{V_{i}^{2}}{S_{i}} e^{j \varphi} \\
& Y_{i}=\frac{1}{Z_{i}}
\end{aligned}
$$

Hesaplanan admitans değerleri bağlı olduğu bara generatör barası ise (-) işaretli olarak, yük barası ise (+) işaretli olarak bara admitans matrisinin ilgili ana köşegen elemanına eklenir. Elde edilen yeni bara admitans matrisinde kritik değerleri aranan baranın 1.satır ve 1. Sütunda, salınım barası 2. satır ve 2. sütunda ve $Y_{11}, Y_{22}$, $Y_{33}$ gibi diğer ana köşegen elemanları da yine ana köşegen üzerinde kalacak şekilde satır ve sütunlar arasında yer değiştirme işlemi yapılır. Denklem (10)'da gösterilen Matris İndirgeme İşlemi yapılarak yeni bara admitans matrisi $2 \times 2$ boyutuna indirgenir.

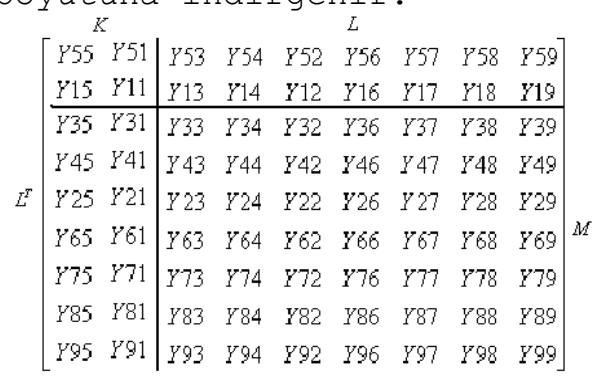

$$
Y 2 \times 2=K-\left[(L)\left(M^{-1}\right)\left(L^{T}\right)\right]
$$

Son olarak elde edilen $2 \times 2$ lik matrisin elemanları ve Bölüm $4.2^{\prime}$ de açıklanan denklem (5) kullanılarak kritik değerleri aranan baranın P-V eğrisi elde edilir [16 ve 20].

\section{BULGULAR VE TARTIŞMA (FINDINGS AND DISCUSSIONS)}

IEEE 6 Baralı Güç Sistemi'nde DSR'siz durum için Powerworld programı çalıştırıldığında elde edilen sonuçlara ilişkin simülatör görünümü Şekil 7'de ve elde edilen güç akışı sonuçları da Tablo 4'te verilmiştir. Sonuçlar incelendiğinde sistemde en fazla (1-4) ve (3-6) nolu hatların yüklendiği görülmektedir. Söz konusu hatlar üzerindeki yüklenme oranı azaltılabilirse bu; hem ilgili hatların rahatlatılarak kayıpların azaltılması hem de tüm sistemin daha güvenli çalıştırılması açısından önemli bir kazanım sağlayacaktır. Bunun için bir sonraki adımda (1-4) ve (3-6) nolu hatlara DSR Modülleri eklenerek analiz yapılmıştır. Kritik değerlerin hesaplanmasında Hat uzunluğu l=550km alınmıştır. $S=P+j Q=70+j 70 \quad$ olduğundan $\quad \varphi=\tan ^{-1}(70 / 70)=45^{\circ} \quad$ olarak ve $\operatorname{Cos} \varphi=\operatorname{Cos}\left(45^{\circ}\right)=0.707$ alınmıştır. 
Tablo 4. DSR'siz durum için güç akışı sonuçları

(Table 4. Power flow result without DSR)

\begin{tabular}{|c|c|c|c|}
\hline Bara No & $P(\mathrm{pu})$ & $\mathrm{Q}(\mathrm{pu})$ & $\mathrm{V}(\mathrm{pu})$ \\
\hline 1 & 1.08 & 0.31 & 1 \\
\hline 2 & 0.50 & 0.84 & 1 \\
\hline 3 & 0.60 & 0.69 & 1 \\
\hline 4 & 0.70 & 0.70 & 0.95 \\
\hline 5 & 0.70 & 0.70 & 0.92 \\
\hline 6 & 0.70 & 0.70 & 0.94 \\
\hline
\end{tabular}

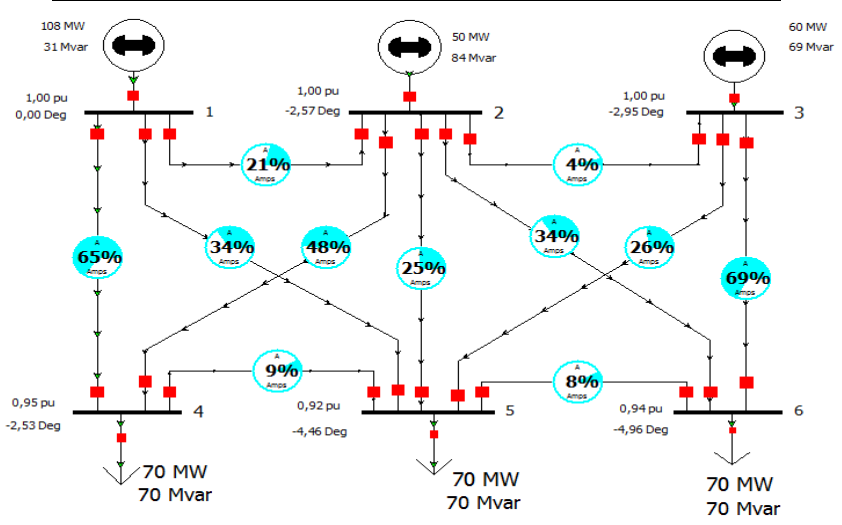

Şekil 7. IEEE 6 baralı güç sistemi powerworld simülatör görünümü (Figure 7. View simulator of powerworld for IEEE 6 bus power system)

Tablo 4'te görülen değerlerin admitansa çevrilip ilgili ana köşegen elemanlarına eklenmesi neticesinde sırasıyla 4, 5 ve 6 numaralı yük baraları için elde edilen $2 \times 2$ boyutundaki indirgenmiş matrisler ile bu matrislerin elemanları kullanılarak hesaplanan hat empedansı ( $Z_{h}$ ) ve Hat admitansı ( $Y_{h}$ ) yine sırasıyla eşitlik 11, 12 ve 13 de verilmiştir. Elde edilen P-V eğrileri ile kritik değerler ise Şekil 8, Şekil 9 ve Şekil 10'da verilmiştir.

$$
\begin{aligned}
& \mathrm{Y} 2 \mathrm{X} 2=\left[\begin{array}{cc}
7.2381-12.6299 \mathrm{i} & -6.0328+12.6652 \mathrm{i} \\
-6.0328+12.6652 \mathrm{i} & 7.1949-12.8068 \mathrm{i}
\end{array}\right] \quad \begin{array}{l}
\mathrm{Z}_{\mathrm{h}}=0.0307+0.0644 \mathrm{i} \\
\mathrm{Y}_{\mathrm{h}}=2.3675-0.1063 \mathrm{i}
\end{array} \\
& \mathrm{Y} 2 \mathrm{X} 2=\left[\begin{array}{ccc}
4.5553-9.1184 \mathrm{i} & -3.4945+9.0926 \mathrm{i} \\
-3.4945+9.0926 \mathrm{i} & 3.9440-8.6848 \mathrm{i}
\end{array}\right] \begin{array}{l}
\mathrm{Z}_{\mathrm{h}}=0.0368+0.0958 \mathrm{i} \\
\mathrm{Y}_{\mathrm{h}}=1.5102+0.3821 \mathrm{i}
\end{array} \\
& \mathrm{Y} 2 \mathrm{X} 2=\left[\begin{array}{cc}
2.8890-6.3282 \mathrm{i} & -1.9614+6.2332 \mathrm{i} \\
-1.9614+6.2332 \mathrm{i} & 2.6902-5.7327 \mathrm{i}
\end{array}\right] \quad \begin{array}{l}
\mathrm{Z}_{\mathrm{h}}=0.0459+0.1460 \mathrm{i} \\
\mathrm{Y}_{\mathrm{h}}=1.6565+0.4056 \mathrm{i}
\end{array}
\end{aligned}
$$

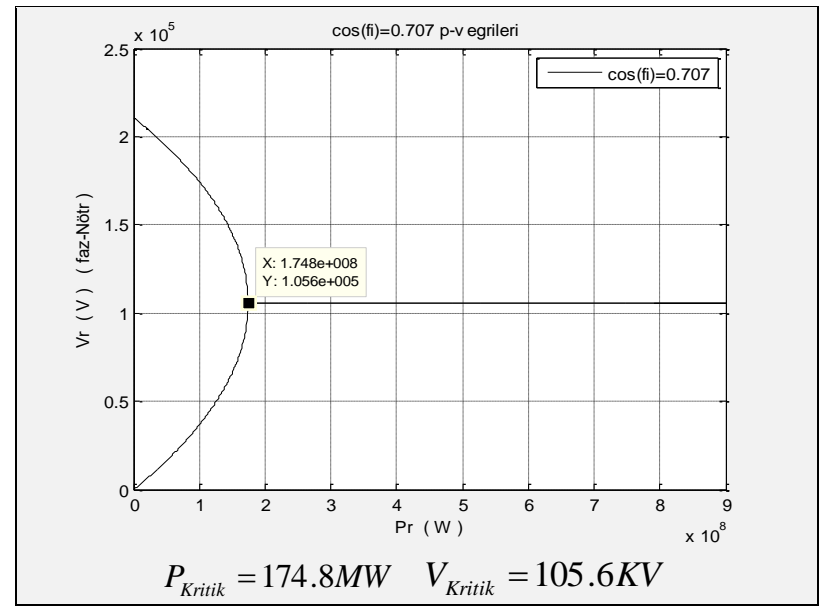

Şekil 8. 4 Nolu Bara P-V eğrisi ve kritik değerler 
(Figure 8. P-V curve and critical values for bus 4)

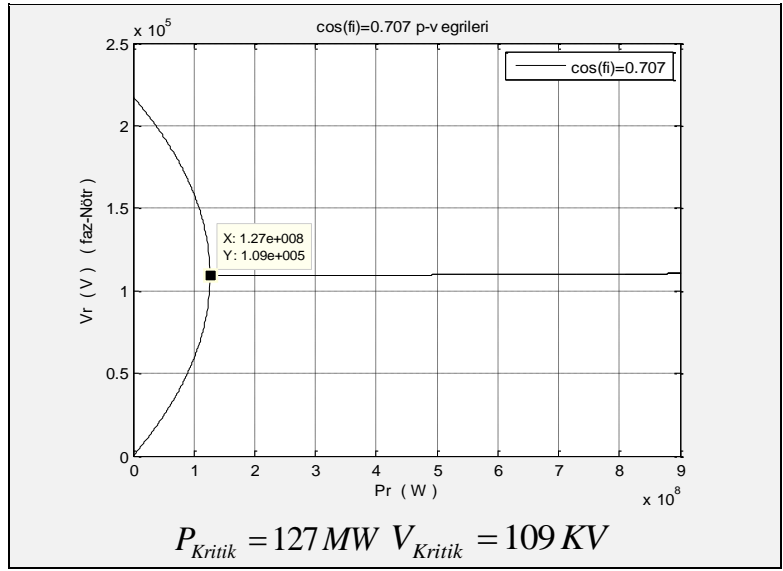

Şekil 9. 5 Nolu bara P-V eğrisi ve kritik değerler (Figure 9. P-V curve and critical values for bus 5)

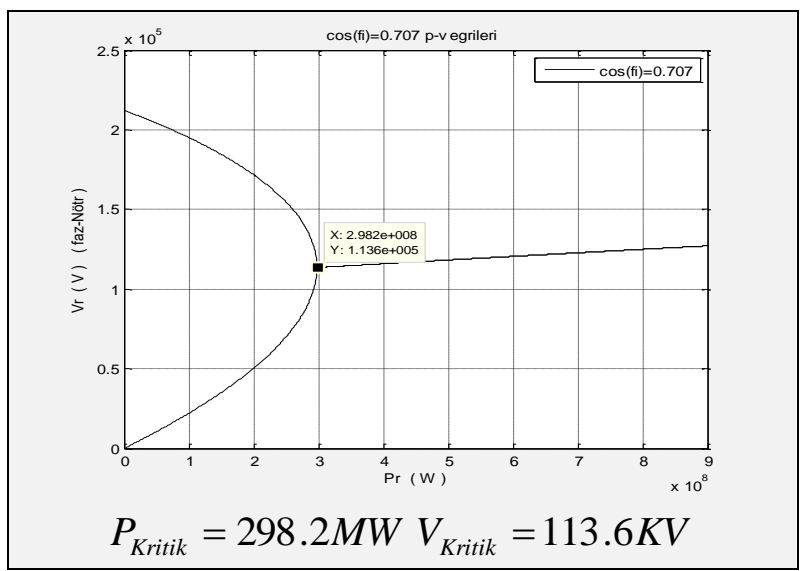

Şekil 10. 6 nolu bara P-V eğrisi ve kritik değerler (Figure 10. P-V curve and critical vlues for bus 6)

Analiz sonucunda sistemde DSR modülleri bulunmadığı durumda 4 numaralı yük barasının kritik değerleri: $P_{\text {kritik }}=174.8 M W ， \quad V_{\text {Kritik }}=105.6 K V$ ， 5 numaralı yük barasının kritik değerleri: $P_{\text {kritik }}=127 M W, \quad V_{K r i t i k}=109 K V$ ve 6 numaralı yük barasının kritik değerleri ise $P_{\text {kriti }}=298.2 \mathrm{MW} \quad V_{\text {Kritik }}=113.6 \mathrm{KV}$ olarak elde edilmiştir. Sistemde sırasıyla \%65 ve \%69 yüklenme oranıyla en çok yüklenmenin görüldüğü 1-4 ve 3-6 hatlarına DSR modülleri bağlanmıştır. DSR Modüllerinin devreye gireceği hat akımı değeri olan aktivasyon akımı 100A, hattan akacak en büyük akım değeri olan maksimum akım limiti 500A seçilmiş, DSR endüktansı sistemdeki varsayılan değer olan modül başına $47 \mu \mathrm{H}$ olarak alınmıştır. Bu değerlere göre güç akışı yapılmıştır. Powerworld programı çalıştırıldığında elde edilen sonuçlara ilişkin simülatör görünümü Şekil 11'de, güç akışı sonuçları Tablo 5' te verilmiştir. 


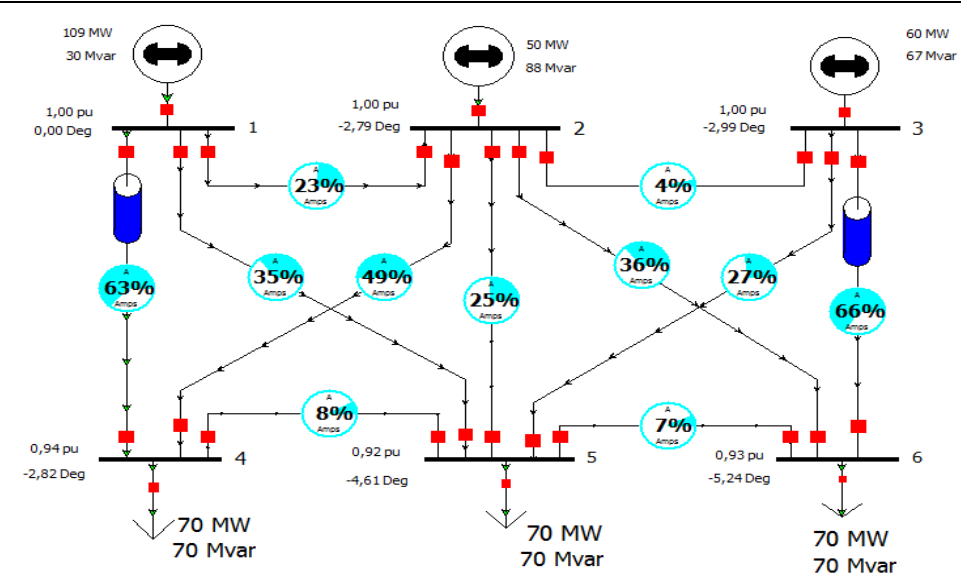

Şekil 11. IEEE 6 Baralı Güç Sistemi simülatör görünümü (Figure 11. View Simulator for IEEE 6 Bus Power System)

Tablo 5. DSR eklenmiş durum için güç akışı sonuçları

(Table 5. Power flow results for DSR added state)

\begin{tabular}{|c|c|c|c|}
\hline Bara No & $\mathrm{P}(\mathrm{pu})$ & $\mathrm{Q}(\mathrm{pu})$ & $\mathrm{V}(\mathrm{pu})$ \\
\hline 1 & 1.09 & 0.30 & 1 \\
\hline 2 & 0.50 & 0.88 & 1 \\
\hline 3 & 0.60 & 0.67 & 1 \\
\hline 4 & 0,70 & 0.70 & 0.94 \\
\hline 5 & 0,70 & 0.70 & 0.92 \\
\hline 6 & 0,70 & 0.70 & 0.93 \\
\hline
\end{tabular}

Tablo 6'da görülen değerlerin admitansa çevrilip ilgili ana köşegen elemanlarına eklenmesi neticesinde sırasıyla 4, 5 ve 6 numaralı yük baraları için elde edilen $2 \times 2$ boyutundaki indirgenmiş matris ve bu matrisin elemanları kullanılarak hesaplanan hat empedansı ( $Z_{h}$ ) ve Hat admitansı $\left(Y_{h}\right)$ yine sırasıyla eşitlik 14, 15 ve 16 da verilmiştir. Elde edilen P-V eğrileri ile kritik değerler de sırasıyla Şekil 12, Şekil 13 ve Şekil 14'te verilmiştir.

$$
\left.\mathrm{Y} 2 \mathrm{X} 2=\left[\begin{array}{cc}
7.2857-12.5792 \mathrm{i} & -5.4428+12.3341 \mathrm{i} \\
-5.4428+12.3341 \mathrm{i} & 7.0555-12.6529 \mathrm{i}
\end{array}\right] \quad \begin{array}{l}
\mathrm{Z}_{\mathrm{h}}=0.0299+0.0679 \mathrm{i} \\
\mathrm{Y}
\end{array}\right] \quad \mathrm{Y}_{\mathrm{h}}=3.4557-0.5638 \mathrm{i}
$$

$$
\begin{aligned}
& Y 2 X 2=\left[\begin{array}{cc}
4.8869-9.0833 \mathrm{i} & -3.1870+8.9578 \mathrm{i} \\
-3.1870+8.9578 \mathrm{i} & 4.1897-8.8066 \mathrm{i}
\end{array}\right] \quad \begin{array}{l}
\mathrm{Z}_{\mathrm{h}}=0.0353+0.0991 \mathrm{i} \\
\mathrm{Y}_{\mathrm{h}}=2.7025+0.0257 \mathrm{i}
\end{array} \\
& \mathrm{Y} 2 \times 2=\left[\begin{array}{cc}
3.2492-6.1838 \mathrm{i} & -1.6574+6.0988 \mathrm{i} \\
-1.6574+6.0988 \mathrm{i} & 2.9574-5.8515 \mathrm{i}
\end{array}\right] \begin{array}{l}
\mathrm{Z}_{\mathrm{h}}=0.0415+0.1527 \mathrm{i} \\
\mathrm{Y}_{\mathrm{h}}=2.8919+0.1624 \mathrm{i}
\end{array}
\end{aligned}
$$

En çok yüklenmenin görüldüğü 1-4 ve 3-6 hatlarına DSR modüllerinin bağlanması durumunda 4 numaralı yük barasının kritik değerleri: $P_{\text {kritik }}=164.9 \mathrm{MW}, \quad V_{\text {Kritik }}=102.2 \mathrm{KV}, 5$ numaralı yük barasının kritik değerleri: $P_{\text {kritik }}=118 \mathrm{MW}, \quad V_{\text {Kritik }}=104.6 \mathrm{KV}$ ve 6 numaralı yük barasının kritik değerleri ise $P_{\text {kritik }}=78.38 \mathrm{MW}, \quad V_{\text {Kritik }}=103.5 \mathrm{KV}$ olarak elde edilmiştir. Bir sonraki adımda ise DSR endüktansı $94 \mu \mathrm{H}$ olarak değiştirilmiş diğer tüm değerler ise aynıyla kullanılmış ve sistemdeki yüklenme durumu gözlenmiştir. Simülatör görünümü Şekil 15'te, Elde edilen güç akışı sonuçları Tablo 6'da verilmiştir. 


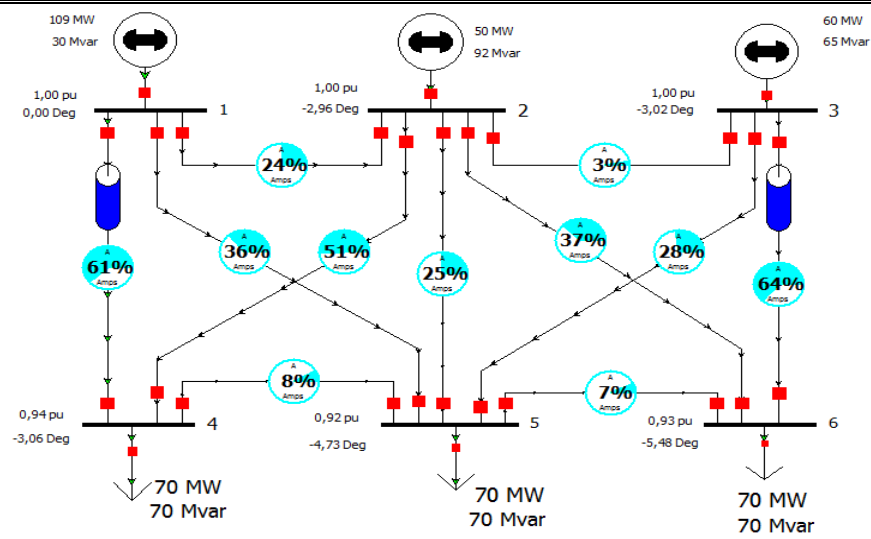

Şekil 15. IEEE 6 Baralı Güç Sistemi simülatör görünümü (DSR=94 $\mu H)$

(Figure 15. View Simulator for IEEE 6 Bus Power System (DSR=94 $\mu \mathrm{H}$ )

Tablo 6. DSR Ekli Durum Güç Akışı Sonuçları

(Table 6. Power Flow Result with DSR. DSR=94 $\mu \mathrm{H}$ )

\begin{tabular}{|c|c|c|c|}
\hline Bara No & $P(p u)$ & $Q(p u)$ & $V(p u)$ \\
\hline 1 & 1.09 & 0.30 & 1 \\
\hline 2 & 0.50 & 0.92 & 1 \\
\hline 3 & 0.60 & 0.65 & 1 \\
\hline 4 & 0.70 & 0.70 & 0.94 \\
\hline 5 & 0.70 & 0.70 & 0.92 \\
\hline 6 & 0.70 & 0.70 & 0.93 \\
\hline
\end{tabular}

DSR'nin modül başına endüktansı $94 \mu \mathrm{H}$ iken 2 numaralı generatör barasından çekilen reaktif gücün artığı, 3 numaralı generatör barasından çekilen reaktif gücün azaldığı diğer değerlerin ise değişmediği görülmektedir.

\section{SONUÇLAR (CONCULUSIONS)}

IEEE 6 Baralı Sistemi üzerinde yapılan analize ilişkin toplu sonuçlar aşağıda Tablo 7, Tablo 8 ve Tablo 9'da verilmiştir.

Tablo 7. Hatlardan akan güç değerleri

(Table 7. Power values to line flows)

\begin{tabular}{|c|c|c|c|c|c|c|}
\hline & \multirow{2}{*}{\multicolumn{2}{|c|}{ DSR Öncesi Güç Akışı }} & \multicolumn{4}{|c|}{ DSR Sonrası Güç Akışı } \\
\hline & & & Aktif & ìç $(\mathrm{MW})$ & Reaktif & Ç $\quad$ (MVAR) \\
\hline $\begin{array}{l}\text { Hat } \\
\text { No }\end{array}$ & $\begin{array}{c}\text { Aktif Güç } \\
(M W)\end{array}$ & $\begin{array}{c}\text { Reaktif Güç } \\
\text { (MVAR) }\end{array}$ & $\mathrm{DSR}=47 \mu \mathrm{H}$ & $\mathrm{DSR}=47 \mu \mathrm{H}$ & $\mathrm{DSR}=94 \mu \mathrm{H}$ & $\mathrm{DSR}=94 \mu \mathrm{H}$ \\
\hline $1-4$ & 58.04 & 25.27 & 55.99 & 24.82 & 54.11 & 24.41 \\
\hline $3-6$ & 42.68 & 50.25 & 40.80 & 48.09 & 39.14 & 46.23 \\
\hline
\end{tabular}

Tablo 8. Yük baraları kritik değerleri

(Table 8. Critical values of load buses)

\begin{tabular}{|c|c|c|c|c|}
\hline & \multicolumn{2}{|c|}{ DSR Öncesi Durum } & \multicolumn{2}{c|}{ DSR Sonrası Durum } \\
\hline Bara No & P Kritik (MW) & V Kritik(KV) $_{\text {Kritik (MW) }}$ & V $_{\text {Kritik (KV) }}$ \\
\hline 4 & 174.8 & 105.6 & 161.3 & 102.2 \\
\hline 5 & 127 & 109 & 117.1 & 104.6 \\
\hline 6 & 298.2 & 113.6 & 77.48 & 103.5 \\
\hline
\end{tabular}


Tablo 9. Hatlardaki yüklenme durumu

(Table 9. Case of loading to lines)

\begin{tabular}{|c|c|c|c|}
\hline Hat No & $\begin{array}{c}\text { DSR Öncesi Durum } \\
\text { (Case of Without DSR) }\end{array}$ & $\begin{array}{c}\text { DSR Sonrasi Durum } \\
\text { (Case Of Add To DSR) } \\
\text { DSR }=47 \mu \mathrm{H}\end{array}$ & $\begin{array}{c}\text { DSR Sonrası Durum } \\
\text { (Case Of Add To DSR) } \\
\text { DSR }=94 \mu \mathrm{H}\end{array}$ \\
\hline $1-2$ & $\frac{\circ 21}{2}$ & $\div 23$ & $\frac{\circ}{2} 24$ \\
\hline $1-4$ & $\div 65$ & $\div 63$ & $\div 61$ \\
\hline $1-5$ & $\div 34$ & $\div 35$ & $\div 36$ \\
\hline $2-3$ & $\div 4$ & $\div 4$ & $\div 3$ \\
\hline $2-4$ & $\div 48$ & $\div 49$ & $\div 51$ \\
\hline $2-5$ & $\div 25$ & $\div 25$ & $\div 25$ \\
\hline $2-6$ & $\div 34$ & $\div 36$ & $\div 37$ \\
\hline $3-5$ & $\div 26$ & $\div 27$ & $\div 28$ \\
\hline $3-6$ & $\div 69$ & $\div 66$ & $\div 64$ \\
\hline $4-5$ & $\div 9$ & $\div 8$ & $\div 8$ \\
\hline $5-6$ & $\div 8$ & $\div 7$ & $\div 7$ \\
\hline
\end{tabular}

Elde edilen sonuçlar incelendiğinde enerji nakil hatlarına DSR modülleri eklenmesinin yük baralarına ait kritik güç ve kritik gerilim değerlerini etkilediği görülmektedir. Enerji nakil hatlarına ilişkin Tablo 9'da görülen mevcut yüklenme oranlarına bakıldığında, $47 \mu \mathrm{H}$ değerinde DSR modülü eklenmesi sonrasında en fazla yüklenme oranına sahip olan (1-4) ve (3-6) hatlarında yüklenme oranı düşerken (1-2), (1-5), (24), (2-6) ve (3-5) hatlarında yüklenme oranının arttığı, (4-5) ile (56) hatlarında yüklenme oranının düştüğü ve (2-3) ile (2-5) hatlarında ise yüklenme oranının değişmediği görülmektedir. DSR modülünün endüktansı $94 \mu \mathrm{H}$ olarak arttırıldığında en fazla yüklenme oranına sahip olan (1-4) ve (3-6) hatlarında yüklenme oranı önceki duruma göre biraz daha düşerken (1-2), (1-5), (2-4), (2-6) ve (3-5) hatlarında yüklenme oranının önceki duruma göre biraz daha arttığı, (2-5), (4-5) ve (5-6) hatlarında yüklenme oranının önceki durum ile aynı düzeyde olduğu ve (23)hattında ise oranının önceki duruma göre biraz daha düştüğü görülmektedir. Ayrıca en fazla yüklenme oranına sahip olan (1-4) ve (36) hatlarından akan güç değerlerine ilişkin Tablo 7 incelendiğinde DSR'nin endüktans değerine bağlı olarak hatlardan akan güç değerlerinin düştüğü görülmektedir. Diğer taraftan Tablo 5 ve Tablo 6'daki güç akışı sonuçları incelendiğinde DSR'nin modül başına endüktansının $94 \mu \mathrm{H}$ olarak değiştirilmesiyle 2 numaralı generatör barasından çekilen reaktif gücün artığı, 3 numaralı generatör barasından çekilen reaktif gücün azaldığı diğer değerlerin ise değişmediği görülmektedir.

\section{TARTIŞMA (DISCUSSION)}

Güç sistemlerinde yük değişimlerine bağlı olarak yük baralarının gerilimleri de sürekli değişmektedir. Yük arttıkça gerilim azalır ve gerilimin azalması da sistemin çalışmasını zorlaştırır. Bu sebeple bara gerilim genliklerinin belirli bir sınırın altına düşmemesi gerekir. İşte gerilim genliğinin bu sınır değeri ile bu değere karşılık gelen faz açısı ve aktif güç değerleri sistemin kritik değerleridir [6]. Kritik değer esasları göz önüne alınırsa Kritik gücün azalması sistemden çekilebilecek maksimum gücün azalması anlamına geleceğinden olumsuz bir durumdur. Ancak kritik gerilimin azalması gerilimin daha az yükseltilerek sistemin kararlı halde tutulabileceği anlamına geldiğinden olumlu bir durumdur. Diğer taraftan gerilimin daha az yükseltilerek sistemin kararlı halde tutulabilmesi güç sistemi işletme maliyetini de azaltacağından yine olumlu bir durumdur. Analiz sonuçları göz önüne alındığında DSR modüllerinin kullanımı güç sisteminde aşırı yüklenen hatları rahatlatarak hatlardan taşınabilecek güç ile generatörlerden çekilebilecek gücü ve kararlılık değerlerini kontrol etme olanağı sağlamaktadır. DSR modülünün endüktans değerine bağlı olarak sistemdeki etkisi de değişmektedir. DSR modüllerinin sistemde hangi noktalara 
konumlandırılacağı, sistemde kullanılması gereken modül sayısının ne olacağı ve bu uygulamanın maliyeti konularında ayrıntılı analizler yapılarak DSR modülleri kullanılabilir. Artan nüfusa bağlı olarak bireysel ve endüstriyel enerji talebi hızla artmaktadır. Fiziki ve ekonomik sebeplerle güç sistemlerinin boyutlarının genişletilmesinin giderek zorlaştığı günümüz dünyasında mevcut güç sistemlerinin boyutları değiştirilmeden daha verimli şekilde kullanılabilmesi açısından DSR aygıtlarının kullanımı etkili bir çözüm olarak görünmektedir.

\section{KAYNAKLAR (REFERENCES)}

[1] Ertay, M.M. ve Aydoğmuş, Z., (2011). Güç Sistemlerinde FACTS Uygulamaları. 6th International Advanced Technologies Symposium (IATS'11), Elazığ, Türkiye, Bildiriler Kitabı, ss:370-375.

[2] Çifci, A., (2015). Facts Cihazları Kullanılan Elektrik Güç Sistemlerinde Enerji Fonksiyonu İle Gerilim Kararlılığı Analizi. Doktora Tezi, Elektrik Elektronik Mühendisliği, Fen Bilimleri Enstitüsü, Sakarya Üniversitesi, Sakarya, Türkiye.

[3] Kara, A. ve Yalçınöz, T., (2005). Esnek Ac İletim Sistemlerinde Kullanılan Cihazlar ve Tcr, Svc, Tsr Yapılı Paralel Kompanzatörlerin Yük Gerilimine Etkisinin Matlab Ortamında Incelenmesi. II. Mühendislik Bilimleri Genç Araştırmacılar Kongresi-MBGAK 2005, İstanbul, Türkiye.

[4] Döşoğlu, M.K., (2010). Rüzgâr Santralinde Gerilim ve Güç Kontrolünün Facts Cihazları İle İncelenmesi. Yüksek Lisans Tezi, Elektrik Eğitimi, Fen Bilimleri Enstitüsü, Düzce Üniversitesi, Düzce, Türkiye.

[5] Çifci, A., (2015), Facts Cihazları Kullanılan Elektrik Güç Sistemlerinde Enerji Fonksiyonu İle Gerilim Kararlılığı Analizi. Doktora Tezi, Elektrik Elektronik Mühendisliği, Fen Bilimleri Enstitüsü, Sakarya Üniversitesi, Sakarya, Türkiye,

[6] Bakır, H., (2018). Güç Sistemlerinde Facts Cihazlarının Optimal Yerleşim Noktalarının Belirlenmesi. Yüksek Lisans Tezi, Elektrik Elektronik Mühendisliği, Fen Bilimleri Enstitüsü, Düzce Üniversitesi, Düzce, Türkiye.

[7] Tosun, S., Öztürk, A., Yalçın, M.A., Döşoğlu, K. ve Güvenç, U., (2011). Güç Sisteminde SVC ve STATCOM Denetleyici Etkilerinin Incelenmesi. 6th International Advanced Technologies Symposium (IATS'11), Elazığ, Türkiye, Bildiriler Kitabı, ss:287-292

[8] Öztürk, A., Bozali, B. ve Tosun, S., (2016). Güç Sistemi Kararlılığını İyileştirecek Facts Cihazlarının Bağlantı Noktasının Belirlenmesi. Düzce Üniversitesi Bilim ve Teknoloji Dergisi. Cilt:4, Sayı:2, ss:812-825.

[9] Grant, I., Shultz, J., Orman, S., Coulllard, J., Kreıkebaum, F., and Broadwater, R., (2014). Initial Field Trials of Distributed Series Reactors and Implications for Future Applications. CIGRE US National Committee Grid of the Future Symposium.

[10] Rahimi, K., Jain, H., and Broadwater, R., (2016). Application of Distributed Series Reactors in Relieving Congestion Costs. IEEE.

[11] Rogers, K.M., (2009), Power System Control with Distributed Flexible AC Transmission System Devices, M.S. Thesis, Depertmant of Electrical and Computer Engineering, University of Illinois, Urbana-Illinois, USA.

[12] Rahimi, K., Jain, H., Broadwater, R., and Hambrick, J., (2015). Application of Distributed Series Reactors in Voltage Balancing. IEEE.

[13] Orman, S., Broadwater, R., Hambrick, J., and Dilek, M., (2014). DSR Design Fundamentals: Power Flow Control. IEEE.

[14] Johal, H., (2008). Distributed Series Reactance: A New Approach To Realıze Grıd Power Flow Control, Ph. Thesis, Depertmant of 
Electrical and Computer Engineering, Georgia Institute of Technology, Georgia, USA.

[15] Nazir, M.N., (2015). Control of Power Flow in Transmission Lines using Distributed Series Reactors. Thesis, Depertmant of Electrical and Computer Engineering, The faculty of the Virginia Polytechnic Institute and State University, BlacksburgVirginia, USA.

[16] Öztürk, A., (2007). Güç Sistemlerindeki Gerilim Kararlılığının Genetik Algoritma İle Íncelenmesi. Doktora Tezi, Elektrik Elektronik Mühendisliği, Fen Bilimleri Enstitüsü, Sakarya Üniversitesi, Sakarya, Türkiye.

[17] http://shodhganga.inflibnet.ac.in/bitstream/10603/16900/13/13_ap pendix.pdf, Erişim Tarihi:20.07.2020.

[18] http://www.yildiz.edu.tr/ inan/LU_Hesap/Power_World_Simulator_Pr

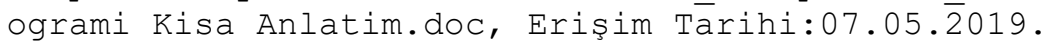

[19] https://www.powerworld.com/company/history, Erişim Tarihi:20.07.2020.

[20] Alaşahan, Y., (2015). Güç Sistemlerinde Harmoniklerin Kritik Değerlere Etkisi, Yüksek Lisans Tezi. Elektrik Eğitimi, Fen Bilimleri Enstitüsü, Düzce Üniversitesi, Düzce, Türkiye. 